chapter which describes the innervation and expected distribution of anaesthesia bony anatomical landmarks, techniques to be employed for successful anaesthesia and some alternative approaches for inferior dental nerve blocks.

It is certain that this book is an excellent and complete complementary text for dental students but to brand it as one for students alone would be to deny the young graduate preparing for postgraduate examinations or the clinician seeking a handy reference text of an extremely useful aide memoire and self-assessment tool. In short, this is a book that would be a valuable addition to any dentist's bookshelf.

N. Docherty

\section{MAXILLOFACIAL TRAUMA AND ESTHETIC FACIAL RECONSTRUCTION, 2ND EDITION}

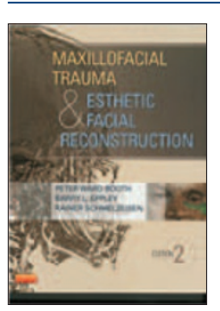

P. Ward Booth, B. L. Eppley,

R. Schmelzeisen

UK: Elsevier

price £239.00; pp 640

ISBN 9781437724202

Changes in the aetiology and management of maxillofacial trauma over the past ten years have led to the need for a new book on this complex area of trauma. Filled with hundreds of superb, full-colour photographs and step-bystep, illustrated procedures, this book is your definitive source on all aspects of managing facial trauma.

World-renowned authors deliver today's foremost guidance on everything from management of the acute trauma patient to the newest materials in surgical trauma and secondary procedures for improved facial appearance. This edition reflects the latest trends, concepts and innovations in the care of patients with facial trauma. It is a comprehensive text dealing with a difficult area, where competing titles are plentiful. Yet a new perspective is provided as facial trauma management and reconstruction are covered in one hardback book. For this reason, together with the sheer quantity and quality of the photos and illustrations, this book is highly recommended. This text offers complete coverage of maxillofacial trauma highlighted by an unparalleled collection of 800 outstanding, full-colour photographs and over 300 highly detailed line drawings that clarify surgical procedures.

An immediate care chapter provides guidance on stabilising the acute patient prior to surgery. All aspects of maxillofacial trauma are covered from management of the acute trauma case to secondary procedures to improve facial appearance and function. Sections are devoted to the definitive management of hard and soft tissue injuries. Topics include a logical approach to orbital trauma and nasoethmoidal, maxillary and panfacial fractures. The reconstruction of large hard and soft tissue loss of the face is demonstrated succinctly and management of traumatic facial nerve injuries including microsurgical repair are illustrated coherently. The psychosocial impact of facial disfigurement is reinforced and the predictors of good long-term outcome are discussed. This edition addresses secondary surgery covering such topics as facial scar management, secondary osteotomies and bone grafting to correct deformities. Bone distraction, used commonly with congenital malformations and secondary rhinoplasty for traumatic nasal deformities, which are associated with a variety of cosmetic and functional issues, are also discussed. A highly illustrated imaging chapter describes the best radiological investigations for each type of injury. A final section is devoted to biomaterials used in craniomaxillofacial surgery and alloplastic biomaterials used in the repair of facial fractures.

Those who face the challenges of facial trauma including trainee and practicing oral, maxillofacial, otolaryngologic and plastic surgeons will find this text particularly valuable.

L. Dunphy

\section{HANDBOOK OF CEPHALOMETRIC SUPERIMPOSITION}

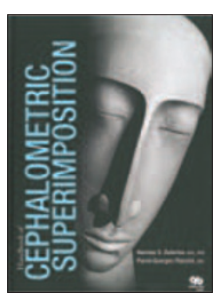

H. D. Duterloo, P-G. Planché

UK: Quintessence

price $€ 78.00$; pp 220

ISBN 9780867155082

This large 'handbook' takes an evidence-based approach to cephalometrics and summarises the available literature on the various topics covered in each chapter, making it very useful as a point of reference. The book goes through the evidence for the structural method, which has previously been somewhat unpopular due to difficulties in its execution and discusses advances in orthodontics, such as the use of digital techniques. These changes in orthodontic practice now make the structural method more accurate and this book describes the evidence for this as it progresses.

It is split into eight chapters, beginning with the "history and origins of the structural method'. Subsequently the reader is led through other wellstructured chapters on how to interpret facial growth and superimposed images, including how to produce manual and computerised structural impositions. It is beautifully illustrated with diagrams, photographs and radiographs referred to throughout and includes a conclusion section at the end of each chapter, making the text more digestible.

Whilst orthodontics seems to be moving towards 3D computerised images, a lot of landmarks are deeper within bone and so being able to correctly understand growth and interpret cephalograms still remains an integral part of orthodontics. Knowledge of anatomy and landmarks from traditional 2D cephalograms is a prerequisite, especially as much of orthodontic thinking on growth is based on cephalometric-based studies. However, as previously mentioned, this book will undoubtedly aid understanding of newer techniques.

Despite being centered on a highly specialised topic, this book is very useful for those in the orthodontic field, as well as those with an interest in furthering their knowledge of cephalometrics and understanding facial growth. Although it may seem challenging from a general dental practitioner's point of view, it offers detailed and well laid out evidence, explanations and instructions on the methods described, as well as knowledge on facial growth and thus has sections that would be of interest to all.

F. N. Janjua-Sharif 